\title{
10-GHz return-to-zero pulse source tunable in wavelength with a single- or multiwavelength output based on four-wave mixing in a newly developed highly nonlinear fiber
}

Clausen, A. T.; Oxenlowe, L.; Peucheret, Christophe; Poulsen, Henrik Nørskov; Jeppesen, Palle; Knudsen, Stig Nissen; Grüner-Nielsen, Lars Erik

Published in:

I E E E Photonics Technology Letters

Link to article, DOI:

$10.1109 / 68.903224$

Publication date:

2001

Document Version

Publisher's PDF, also known as Version of record

Link back to DTU Orbit

Citation (APA):

Clausen, A. T., Oxenlowe, L., Peucheret, C., Poulsen, H. N., Jeppesen, P., Knudsen, S. N., \& Grüner-Nielsen, L. E. (2001). 10-GHz return-to-zero pulse source tunable in wavelength with a single- or multiwavelength output based on four-wave mixing in a newly developed highly nonlinear fiber. I E E E Photonics Technology Letters, 13(1), 70-72. https://doi.org/10.1109/68.903224

\section{General rights}

Copyright and moral rights for the publications made accessible in the public portal are retained by the authors and/or other copyright owners and it is a condition of accessing publications that users recognise and abide by the legal requirements associated with these rights.

- Users may download and print one copy of any publication from the public portal for the purpose of private study or research.

- You may not further distribute the material or use it for any profit-making activity or commercial gain

- You may freely distribute the URL identifying the publication in the public portal 


\title{
10-GHz Return-to-Zero Pulse Source Tunable in Wavelength with a Single- or Multiwavelength Output Based on Four-Wave Mixing in a Newly Developed Highly Nonlinear Fiber
}

\author{
A. T. Clausen, L. Oxenløwe, C. Peucheret, H. N. Poulsen, P. Jeppesen, S. N. Knudsen, and L. Grüner-Nielsen
}

\begin{abstract}
In this letter, a novel scheme for a wavelength-tunable pulse source (WTPS) is proposed and characterized. It is based on four-wave mixing (FWM) in a newly developed highly nonlinear fiber between a return-to-zero (RZ) pulsed signal at a fixed wavelength and a continuous wave probe tunable in wavelength. The corresponding FWM product acts as the WTPS, and is implemented in a 10-Gb/s, 160-km transmission experiment and in a 40-Gb/s multiplexing/demultiplexing experiment. The scheme can be expanded to a multiwavelength WTPS, which is demonstrated for two wavelengths. The introduced penalty using the WTPS compared to the original $\mathrm{RZ}$ pulses is negligible.
\end{abstract}

Index Terms-Demultiplexing, nonlinear optics, optical fiber communication, optical Kerr effect, optical mixing, optical pulse generation, optical time-division multiplexing, wavelength conversion.

\section{INTRODUCTION}

$\mathbf{I}$ N FUTURE optical networks, it is expected that picosecond return-to-zero pulse sources (RZ-PS) tunable in wavelength, with a single or multiwavelength output, are needed in order to increase the capacity. Some schemes that fulfill these requirements are, e.g., mode locking [1] or ring structures [2]. For upgrading an existing RZ-PS with a fixed wavelength to a wavelength-tunable pulse source (WTPS), one suggested method is using the RZ-PS as the pump in super-continuum spectral slicing [3]. In this letter, a novel approach for upgrading to a WTPS is proposed. It is based on the parametric process in a newly developed highly nonlinear fiber (HNLF) between a RZ-PS signal at a fixed wavelength and a continuous wave $(\mathrm{CW})$ probe tunable in wavelength. The FWM product at the output of the HNLF is a replica of the RZ-PS signal, and can be tuned in wavelength by tuning the wavelength of the CW probe. When the RZ-PS signal acts as the pump in a four-wave mixing (FWM) process, the WTPS can be expanded to a multiwavelength WTPS by launching several $\mathrm{CW}$ probes at different wavelengths into the HNLF.

Manuscript received July 27, 2000; revised October 12, 2000. This work was supported in part by the European IST Project METEOR.

A. T. Clausen, L. Oxenløwe, C. Peucheret, H. N. Poulsen, and P. Jeppesen are with the Research Center COM, Technical University of Denmark, DK-2800 Lyngby, Denmark (e-mail: atc@com.dtu.dk).

S. N. Knudsen, and L. Grüner-Nielsen are with Lucent Technologies Denmark, Priorparken 680, DK-2605 Brøndby, Denmark (e-mail: sknudsen@ lucent.com).

Publisher Item Identifier S 1041-1135(01)00491-8.

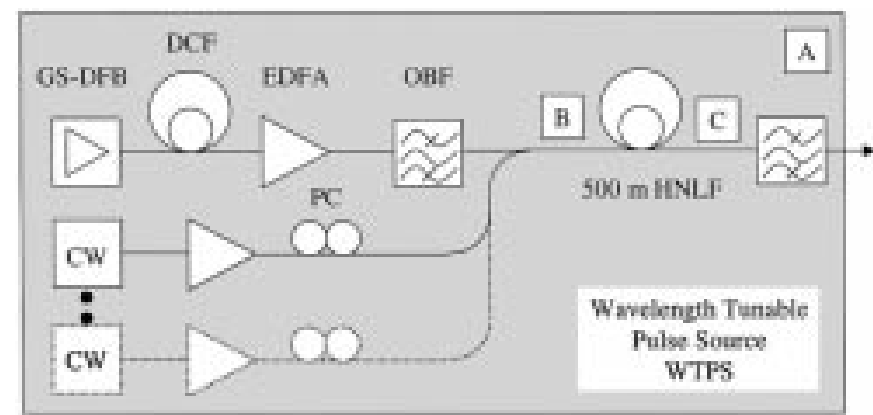

(a)

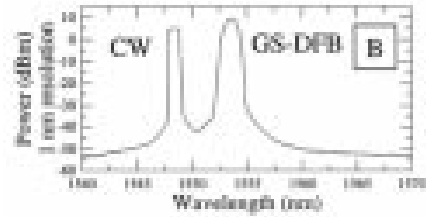

(b)

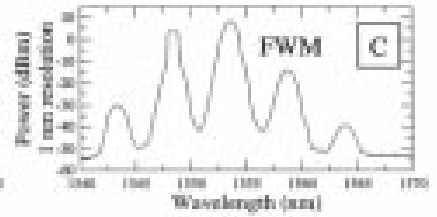

(c)
Fig. 1. (a) Experimental setup of wavelength-tunable pulse source (WTPS). GS-DFB: gain-switched distributed feedback laser. CW: continuous wave. EDFA: erbium-doped fiber amplifier. OBF: optical bandpass filter. PC: polarization controller. (b) Spectrum of input signals to highly nonlinear fiber (HNLF). (c) Output spectrum from HNLF.

\section{WAVELEngth-TunABle PUlSE SOURCE}

In the actual implementation of the WTPS [see Fig. 1(a)], the RZ-PS is a gain-switched DFB (GS-DFB) laser modulated at $10 \mathrm{GHz}$. The full-width at half-maximum (FWHM) of the pulses, after compression in a dispersion compensating fiber (DCF), is $6.3 \mathrm{ps}$. The pulses are amplified and optical bandpass filtered (OBF) before being launched through an asymmetric coupler $(1: 10 \mathrm{~dB})$ into the HNLF. The CW source is a commercially available laser source, with a wavelength $\left(\lambda_{\mathrm{CW}}\right)$ tuning range from $1525 \mathrm{~nm}$ to $1610 \mathrm{~nm}$. The $\mathrm{CW}$ probe is amplified but not filtered, hereby simplifying the operation of the WTPS, when $\lambda_{\mathrm{CW}}$ is tuned. A polarization controller (PC) in front of the coupler allows for aligning the polarization state of the CW probe to be copolarized with the RZ-PS signal. The power levels at the input to the HNLF for the RZ-PS signal and $\mathrm{CW}$ probe are +10 and $+5 \mathrm{dBm}$, respectively, as seen from the input spectrum to the HNLF [Fig. 1(b)]. Because the wavelength of the RZ-PS ( $\lambda_{\mathrm{RZ}}=1553.6 \mathrm{~nm}$ ) corresponds to the zero-dispersion wavelength $\left(\lambda_{0}\right)$ of the HNLF, the RZ-PS is 


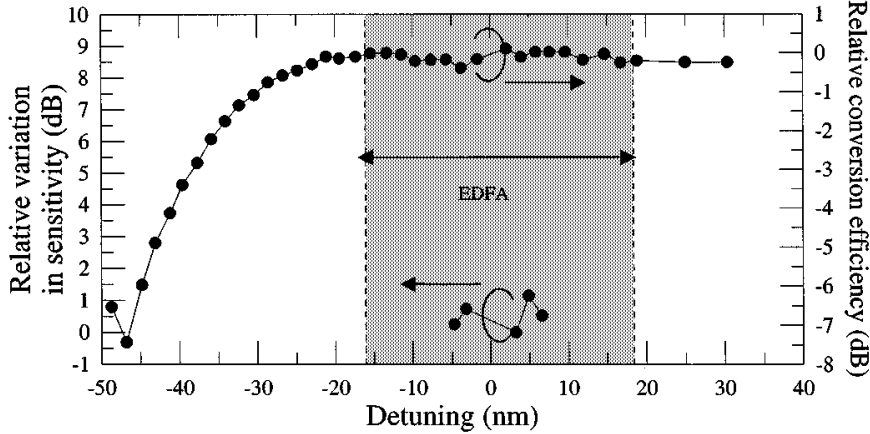

Fig. 2. Relative variation in sensitivity, relative conversion efficiency for HNLF and EDFA gain bandwidth (1535-1570 nm) (marked as grey box) all as function of detuning.

well suited as the pump in an efficient FWM process [4]. Furthermore, the fiber used in this experiment is a newly developed HNLF with a high nonlinear coefficient $\left(\gamma=10.6 \mathrm{~W}^{-1}\right.$ $\mathrm{km}^{-1}$ ). This is achieved by a high-index Germanium-doped core and deeply depressed ring, reducing the effective area to $\sim 12 \mu \mathrm{m}^{2}$. Dispersion-slope, $S$, and attenuation, $\alpha$, are 0.022 $\mathrm{ps} / \mathrm{nm} / \mathrm{km}^{2}$ and $0.87 \mathrm{~dB} / \mathrm{km}$, respectively. Due to the large $\gamma$, the needed length of fiber is reduced significantly compared to standard dispersion shifted fiber often utilized as the nonlinear medium, see e.g., [5], and the length in this implementation is only $\sim 500 \mathrm{~m}$. The advantages of a reduced length of fiber are: a) a reduced impact of environmental influence; and b) a large FWM bandwidth, when combined with a low slope $S$ [4], [6], [7]. In the HNLF, a partly degenerated FWM process generates new frequencies, as seen at the output spectrum from the HNLF [see Fig. 1(c)]. The wavelength of the FWM signal used for the WTPS application, containing a replica of the original pulses, is $\lambda_{\mathrm{FWM}}=\left(2 / \lambda_{\mathrm{RZ}}-1 / \lambda_{\mathrm{CW}}\right)^{-1}$ [5]. Consequently, by tuning $\lambda_{\mathrm{CW}}$, the wavelength $\lambda_{\mathrm{FWM}}$ can be tuned. The converted pulses are optical bandpass filtered and used as the WTPS in the experiments. Because the RZ-PS is used as the pump, the scheme can be expanded to provide multiwavelength WTPS, by launching several $\mathrm{CW}$ probes at different wavelengths into the HNLF, which is indicated with dots in Fig. 1.

\section{WTPS CHARACTERIZATION}

When tuning $\lambda_{\mathrm{CW}}$ from 1546 to $1558 \mathrm{~nm}$, a small increase in pulsewidth, when compared to the pulses from the GS-DFB, is observed, i.e., FWHM $\sim 7$ ps with small variations up to $+0.4 \mathrm{ps}$ over the tuning range. The converted pulses are externally modulated and detected using a $10-\mathrm{Gb} / \mathrm{s}$ transmitter and receiver [see TX and RX in Fig. 3(a)]. In Fig. 2, the variation in sensitivity, relative to the best measured sensitivity, is shown as a function of the detuning $\left(\lambda_{\mathrm{FWM}}-\lambda_{\mathrm{RZ}}\right)$, showing a maximum variation of $\sim 1 \mathrm{~dB}$. In order to estimate the tuning range of the FWM process in the HNLF, a CW pump and probe were launched into the fiber, and the conversion efficiency, defined as the power of the generated FWM product at the output of the fiber divided by the power of the input CW pump [6], versus the detuning was measured and added to Fig. 2. Measured, the FWHM bandwidth of the conversion efficiency is $>68 \mathrm{~nm}$, and estimated to $76 \mathrm{~nm}$ assuming symmetry around $\lambda_{0}$. Consequently, it is expected that the tuning range of the WTPS will

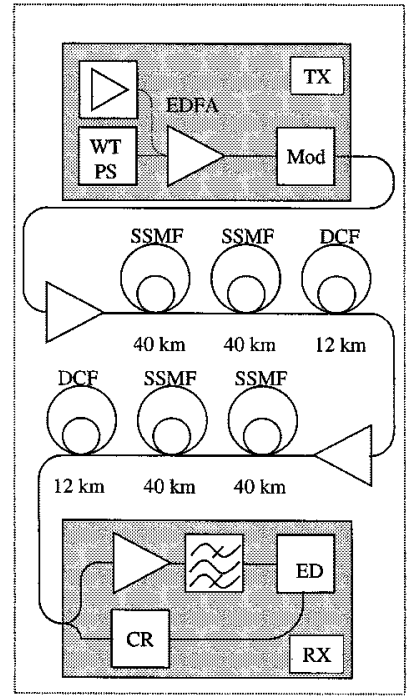

(a)

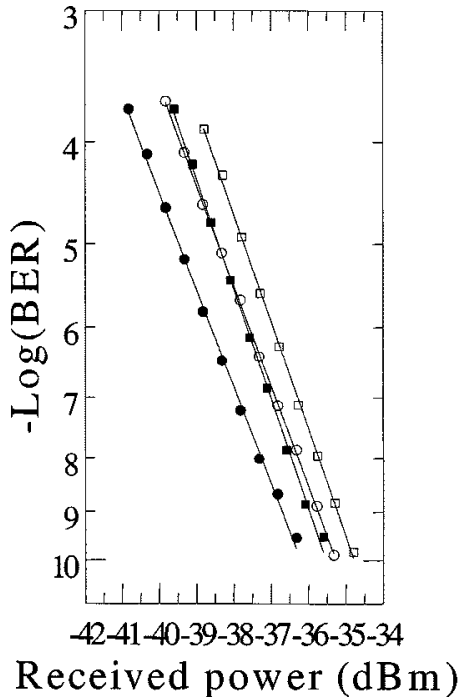

(b)
Fig. 3. (a) Experimental setup of a 10-Gb/s transmission experiment over a total of $160 \mathrm{~km}$ of SSMF and $24 \mathrm{~km}$ of DCF. (b) BER measurements as function of received power: $(\bullet)$ GS-DFB pulses modulated and received; $(O)$ GS-DFB pulses modulated, transmitted, and received; (ם) WTPS pulses modulated and received; ( $\square$ ) WTPS pulses modulated, transmitted, and received.

be limited by the gain bandwidth of the EDFA (also represented in Fig. 2).

\section{TRANSMISSION EXPERIMENT}

In Fig. 3(a), the setup of the transmission experiment is shown. The pulses from the WTPS were externally modulated (PRBS $2^{31}-1$ ) in a $\mathrm{LiNbO}_{3}$ Mach-Zehnder modulator, amplified and launched into two transmission spans, in total $160 \mathrm{~km}$ of standard single mode fiber (SSMF) and $24 \mathrm{~km}$ of DCF [8]. In the receiver, the signal was preamplified, optical bandpass filtered (OBF), and detected in an error-detector (ED), which was triggered by an electrical clock-recovery (CR). For comparison, the same experiment was carried out using the original pulses from the GS-DFB, and the corresponding bit error rate (BER) measurements are shown in Fig. 3(b). The penalty for converting the pulses from $1553.6 \mathrm{~nm}$ to 1557 $\mathrm{nm}$ using the above scheme is $\sim 0.7 \mathrm{~dB}$. For transmitting the original pulses, the introduced penalty is $\sim 1 \mathrm{~dB}$, whereas the penalty for transmitting the converted pulses is $\sim 0.7 \mathrm{~dB}$. This is explained by an additional OBF in front of the two transmission spans, which reduce the amplified spontaneous emission noise from the amplifiers. In conclusion, the WTPS pulses have approximately the same performance as the original pulses in terms of transmission properties.

\section{MultiPlexing/DemultipleXing to $40 \mathrm{~Gb} / \mathrm{s}$}

To evaluate the WTPS pulses for optical time-division-multiplexing (OTDM) systems, the $10-\mathrm{Gb} / \mathrm{s}$ modulated signal was multiplexed to $40 \mathrm{~Gb} / \mathrm{s}$ using fiber delays. The signal was subsequently demultiplexed to $10 \mathrm{~Gb} / \mathrm{s}$ using a 10-GHz modulated electroabsorption modulator (EAM) and detected. In Fig. 4, the BER measurements are depicted. The penalty for multiplexing and demultiplexing the WTPS signal is $\sim 0.9 \mathrm{~dB}$, which represents a negligible increase compared with the penalty for the 


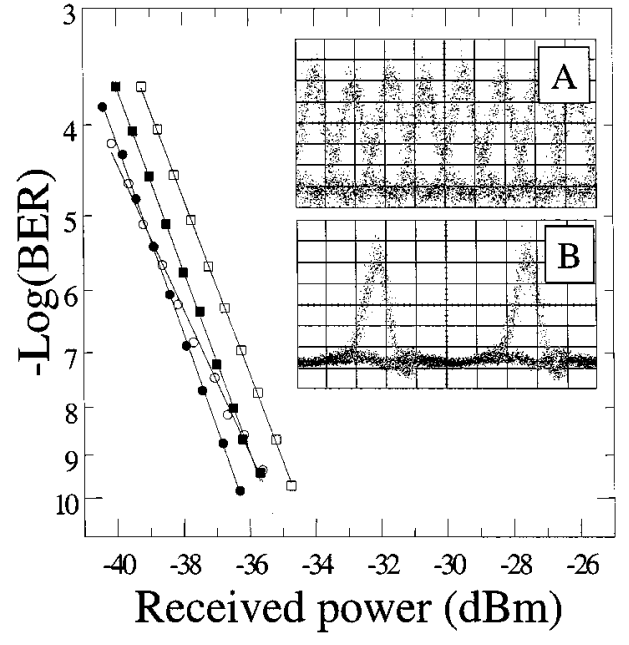

Fig. 4. BER measurements: $(\bullet)$ GS-DFB pulses modulated and received; (O) GS-DFB pulses modulated, multiplexed to $40 \mathrm{~Gb} / \mathrm{s}$, demultiplexed to $10 \mathrm{~Gb} / \mathrm{s}$, and received; ( $\square$ ) WTPS pulses modulated and received; ( $\square$ ) WTPS pulses modulated, multiplexed to $40 \mathrm{~Gb} / \mathrm{s}$, demultiplexed to $10 \mathrm{~Gb} / \mathrm{s}$, and received. Inset A: eye diagram of WTPS $40-\mathrm{Gb} / \mathrm{s}$ signal. Inset B: eye diagram of demultiplexed WTPS $10-\mathrm{Gb} / \mathrm{s}$ signal.

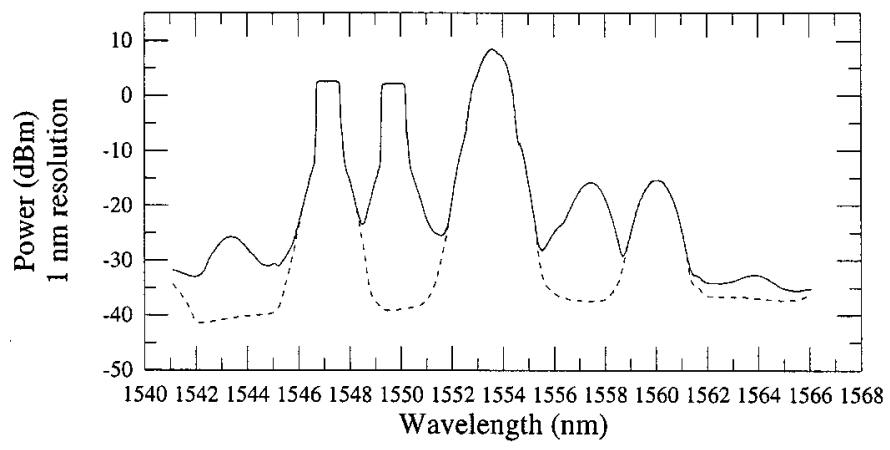

Fig. 5. Output spectrum from HNLF with one input $\mathrm{CW}$ probe (dotted line) and two input $\mathrm{CW}$ probes (full line).

original signal, i.e., $\sim 0.7 \mathrm{~dB}$. The insets in Fig. 4 show the eye diagrams of the $40-\mathrm{Gb} / \mathrm{s}$ WTPS signal and the corresponding $10-\mathrm{Gb} / \mathrm{s}$ demultiplexed signal.

\section{MultiWAVELENGTH WTPS}

In Fig. 1, it is indicated that the principle of the setup can be expanded to a multiwavelength WTPS. This is demonstrated for a two-wavelength WTPS, by injecting two CW probes into the HNLF. The wavelengths of the CW probes are 1547 and $1550 \mathrm{~nm}$, respectively, which generate pulses at 1557 and $1560 \mathrm{~nm}$. The output spectrum from the HNLF is represented in Fig. 5 for one and two CW input probes, showing no measurable difference in conversion efficiency. Furthermore, no impact on the pulsewidth was observed, i.e., at 7.0 ps FWHM, for one and two CW probes. The WTPS pulses at $1560 \mathrm{~nm}$ were filtered out, modulated, and received for one- and two-input
$\mathrm{CW}$ probes. The corresponding BER measurements showed a negligible penalty of $0.3 \mathrm{~dB}$ ascribed to insufficient filtering. In conclusion, the principle of WTPS can be expanded to a multiwavelength WTPS. Pump depletion, bandwidth management, filtering, and crosstalk between the different signals will determine the actual number of available wavelengths generated with this scheme.

\section{CONCLUSION}

In this letter, a novel tunable RZ pulse source is proposed. It is based on four-wave mixing in a highly nonlinear fiber between a $\mathrm{RZ}$ pulsed signal at a fixed wavelength and a $\mathrm{CW}$ probe tunable in wavelength. The pulses from the WTPS show the same performance as the original pulses in terms of pulsewidth, transmission properties, and for multiplexing/demultiplexing from 40 to $10 \mathrm{~Gb} / \mathrm{s}$. The tuning bandwidth is demonstrated over $14 \mathrm{~nm}$, but due to the large bandwidth of the HNLF, i.e., $76 \mathrm{~nm}$, it is believed that the tuning bandwidth is significantly larger and limited only by the EDFA gain profile. The technique is demonstrated to be upgradable to multiwavelength RZ pulse source.

\section{ACKNOWLEDGMENT}

The authors would like to thank Opto + for providing the GS-DFB laser. They would also like to thank KDD for providing the EAM.

\section{REFERENCES}

[1] R. Ludwig, S. Diez, A. Ehrhardt, L. Kuller, W. Pieper, and H. G. Weber, "A tunable femtosecond modelocked semiconductor laser for applications in OTDM-systems," IEICE Trans. Electron., vol. E81-C, no. 2, pp. $140-145,1998$.

[2] A. D. Ellis, R. J. Manning, I. D. Phillips, and D. Nesset, "1.6 ps pulse generation at $40 \mathrm{GHz}$ in phaselocked ring laser incorporating highly nonlinear fiber for application to $160 \mathrm{Gbit} / \mathrm{s}$ OTDM networks," Electron. Lett., vol. 35, no. 8, pp. 645-646, 1999.

[3] Y. Takushima and K. Kikuchi, "10 GHz, over 20-channel multiwavelength pulse source by slicing super-continuum spectrum generated in normal-dispersion fiber," Photon. Technol. Lett., vol. 11, no. 3, pp. 322-324, 1999.

[4] K. Inoue, "Four-wave mixing in an optical fiber in the zero-dispersion wavelength region," J. Lightwave Technol., vol. 10, no. 11, pp. 1553-1561, 1992.

[5] P. H. Hedekvist, M. Karlsson, and P. A. Andrekson, "Fiber four-wave mixing demultiplexing with inherent parametric amplification," J. Lightwave Technol., vol. 15, no. 11, pp. 2051-2058, 1997.

[6] M. Onishi, T. Okuno, T. Kashiwada, S. Ishikawa, N. Aksaka, and M. Nishimura, "Highly nonlinear dispersion-shifted fibers and their application to broadband wavelength converter," Opt. Fiber Technol., vol. 4, no. 2, pp. 204-214, 1998.

[7] O. Aso, M. Tadakuma, and S. Namiki, "More than $91 \mathrm{~nm}$ broadband four-wave mixing based fiber parametric wavelength converter," in 25th Eur. Conf. Optical Communication (ECOC'99), Nice, France, 1999, Post-deadline Paper PD1-10, pp. 20-21.

[8] L. Grüner-Nielsen, S. N. Knudsen, T. Veng, B. Edvold, and C. Larsen, "Design and manufacture of dispersion compensating fiber for simultaneous compensation of dispersion and dispersion slope," in Tech. Dig. Optical Fiber Communication Conf. (OFC'99), San Diego, CA, 1999, Paper WM13, pp. 232-234. 